\title{
University Students' Knowledge about Diabetes' Causes, Symptoms and Treatments
}

\author{
Hussain Matrook Alnajadat \\ Department of Educational Psychology, Tafila Technical University, Tafila, Jordan \\ E-mail: h_ngadat@yahoo.com
}

Received: August 1, 2017 Accepted: Sep. 18, 2017 Published: November 1, 2017

doi:10.5296/jse.v7i4.11807 URL: https://doi.org/10.5296/jse.v7i4.11807

\begin{abstract}
The purpose of this study is to investigate the degree of knowledge of the students at Tafila Technical University (TTU) about diabetes in terms of its causes, symptoms and treatments. The sample of the study consisted of 171 male and female students enrolled at the Faculty of Educational Sciences for the academic year 2015/2016. To achieve the aims of the study, the researcher developed a questionnaire consisting of 25 items distributed over two groups, ten items consisted of four multiple answers, while the other 15 ones were based on a yes-or-no pattern verified by the norms of honesty and consistency. The results of the study showed that there were statistically significant differences in the degree of knowledge of the students about diabetes, attributed to first-degree relatives with diabetes or not. In addition, the results also showed that there were no statistically significant differences in the degree of knowledge about diabetes attributed to gender, major and academic year.
\end{abstract}

Keywords: University, Students, Diabetes. 


\section{Introduction}

Diabetes is one of the disturbing diseases to all ages. In addition to its effects and its frightening complications such as heart attacks (cardiovascular), blindness (retinopathy), kidney failure (nephropathy) and amputation, that causes inability to an infected person. The treatment cost of diabetes is one of the highest in Jordan in particular and in the world in general. Although diabetes is one of the diseases of the time, but it was known since the ancient ages. At the beginning of $200 \mathrm{BC}$, the Greek physician Aretaeus recorded that some patients had the symptoms of constant thirst (Polydipsia), excessive urination (Polyuria); he named this condition as 'flowing through' or 'diabetes', which means the frequent urination. In 1675, Thomas Willis added the word (Mellitus), which means (Honey) in Latin, he noticed that the blood and urine of some of diabetics have a sweet taste. After a period of time, the disease became well known as Diabetes Millitus or diabetes (Alhameed, 2008).

Diabetes as the most chronic diseases cannot be treated by taking medicine for a specific time, but it can be coexisted and controlled normally by a patient's commitment in completing the treatment requirements. Diabetes occurs when there is an actual or relative decrease concentration in the insulin hormone, which causes high blood glucose, producing complaints and clinical symptoms, acute or lifelong complications in different body systems (The National Centre for Diabetes Endocrinology and Genetics, 2011, A).

Generally, there are two major types of diabetes: diabetes type 1 and diabetes type 2. Type1 diabetes, also called Insulin-dependent diabetes or Juvenile diabetes, usually develops over children or young adults. Type 1 diabetes is the least common, with just $10-15 \%$ of all diabetic people. In this type, the pancreas cannot produce insulin because the cells that produce insulin are destroyed by the body's own immune system. It is also worth to mention that patients of Type 1 diabetes have to take insulin on a daily basis besides diet programs and sports (Information Association, 2010). Type 2 diabetes is known as non-insulin-dependent or adult-onset. This type gradually occurs and is detected by chance when doing any regular medical check-up. In this type, the pancreas produces an insufficient amount of insulin, or the resistance of the cells and tissues is larger than the function of insulin, because of the lack of insulin receptors or because of existing antibodies against these receptors that prevent insulin from reaching respecter causing a high level of blood sugar (Alhameed, 2008).

So far, the reasons behind diabetes are still unknown, but there are factors that can help increase the risk of diabetes as demonstrated by Almishal (2010): 1) Genetics: If a family member has type 1 diabetes, the rest of the family members shall have tendency to be infected. 2) Obesity: Weight gain leads to physical and psychological stresses and reduces the effectiveness of insulin. Therefore, the risk of insulin-dependent diabetes increases in obese (overweight) people. 3)Diseases and psychological crises: Diseases and surgeries, as well as psychological crises such as anxiety and tension, the burden of excess on the pancreas lead to emerge the symptoms of diabetes in those who have tendency to it. 4) Drugs: The long-term of using diuretics, cortisone compounds and contraceptive pills lead diabetes symptoms to appear in the most willing people. 5) Infections: Some viral infections help change the body immune response that leads to incidence the insulin-dependent diabetes. 6) Alcohol: The 
alcoholic addiction works to damage the pancreas and helps cause the symptoms of diabetes. 7) Physical inactivity: The lack of motor activity leads to diabetes in those who have tendency to it. 8) Pregnancy: Pregnancy could lead the call of gestational diabetes in those who are ready to occur.

It is known that diagnosing diseases as well as diabetes in their early stages is very important, because most of diabetic people are infected five years earlier. By the passage of time, some of diabetic people suffer from the risk of such complications as problems in eyes, heart, kidney or nerves and feet. Accordingly, it is important to know the early symptoms of diabetes, help control and treat it early so as to minimize its complications in a safe manner: Increased thirst, general weakness (fatigue), slow healing wounds or frequent infections, hands and feet tingling, a state of Sexual dysfunction may occur for men, a state redness in face, swollen and tender gum (The National Centre for Diabetes Endocrinology and Genetics, 2011, B). Excessive urination at night, blurry vision, weight loss, dry skin and vomiting (Centres for Disease Control and Prevention, 2007).

Diabetes type 2 in Jordan is highly spreading and is still increasing. Furthermore, half of the diabetes patients do not control themselves; therefore, they need to make use of beneficial programs to acquire encouraging behaviors to lose weight, such as practicing sports that have physical activity (Ajlouni, Khader, Batieha, Ajlouni, \& El-Khateeb, 2007). World Health Organization statistics indicates that the number of people with diabetes increased from 108 in 1980 to 422 million in 2014. In addition, diabetes spreading around the world among adults increased to those over the age of 18 from $4.7 \%$ in 1980 to $8.5 \%$ in 2014 (World Health Organization, 2014).

One of the studies warns from expected rates risk of increasing diabetes in Jordan. It indicates that in 2050 , diabetes will be increasing up to about $30 \%$ of the population by three-quarters to three million (Brown et al., 2009). It is worth mentioning that the early intervention has many benefits to decrease diabetes type 2 (UK Prospective Diabetes Study Group, 1998).

This study came to examine the degree at which the students at the Faculty of Education at Tafila Technical University TTU have any medical information to know more about diabetes as to its causes, symptoms and treatments. Actually, those students represent an important group in the society; they will also be future leaders and/or teachers of future generations. Unforgettably, those students have sons, brothers or relatives with diabetes, or they may have diabetes themselves.

\section{Related Literature}

There are several studies discussed the topic of the awareness of students relating to diabetes and its causes, symptoms and treatments, as the following:

Study of Arshidat (2007) 'The effect of the physical activity and dieting on type 2 diabetes patient' aimed to identify the effect of physical activity (walking) and dieting in controlling the percentage of blood sugar in patients with type 2 diabetes. Moreover, it was to show the disadvantages of obesity over the study sample. The sample was selected from Yarmouk University staff, and the number of volunteers was between 35-50 years with the blood sugar 
ranging between 106-330 mg/dl. The sample of the study offered to perform hiking programs beside diet programs for nine weeks. The results showed that: 1) walking and diet considerably help to improve the level of blood sugar in patients of type 2,2) walking and dieting did not contribute to weight loss in people with type 2 diabetes, 3) walking did not contribute to maintaining the proportion of diabetes in blood in the delayed follow-up measurement, and 4) statistically significant differences exist in the impact of walking on obesity in patients with type 2 diabetes between post-direct and follow-up measures in favor of the immediate dimension.

The study of Gunay et al. (2006) aimed to explore the factors that affect the extent of knowledge of adults with diabetes in Narlidere, Turkey. The sample of this study consisted of 479 adults above the age of 30 years (61\% females and 39\% males). They were divided into two groups; individuals with diabetes or having a relative with diabetes and the without diabetes or not having a relative with diabetes. The findings of the study showed that: 1) the average score of respondents' knowledge of diabetes was $62.9 \%, 2$ ) the average score of data about diabetic patients or infected relatives was $68.3 \%, 3$ ) the average score about non-diabetic patients or their non-diabetic relatives was $60.7 \%$, and 4) the data about the first group was larger than the second group.

The study of Ajlouni, Khader, Batieha, Ajlouni, El-khateeb (2007) entitled "The increase in the incidence of diabetes in Jordan during 10 years" aimed to determine how highly type 2 diabetes has prevailed through the past 10 years. It is also to measure the success of a preventive diabetes program by following certain diets and practicing physical activities. The study found that type 2 diabetes has increased for the past ten years, and more than $50 \%$ of patients do not follow certain diets nor practice any physical activities or sports suiting their ages and their health conditions.

The study of Alhayari (2002) entitled "Children with diabetes and their families: the role of social work" aimed to identify the prominent problems which mothers and children suffer from as a result to diabetes infection. Accordingly, a questionnaire was designed to include such variables as education, age category, occupation of parents, number of family members and child's monthly income. In addition to a child's characteristics related to such various factors as age, gender and order among brothers and sisters, the study applied to children with diabetes at the University of Jordan Hospital as well as the clients of the National Centre for Diabetes, Endocrinology and Genetics at the age of 6-12 from March 15 to April 25, 2002. The total number of children was 60 divided into 29 boys and 31 girls. The results indicated that children have belonged to families consisting of a mother and father except for one orphan child; also, most of the children belonged to families of seven members. Eventually, the incidence of diabetes infection was $48.3 \%$ among boys and $51.7 \%$ among girls, while the most important problems were excessive parental control and protection.

Bennett, Polak, and Arland (1982) conducted a study entitled 'Cognitive and behavioral information about insulin-dependent diabetes by infected children and their parents' aimed at measuring infected children and their parents' knowledge about type 1 diabetes in terms of its causes, symptoms and treatments. The study attempted three questions as to the information 
generally available for children and their parents, the ability of children and their parents to face the diabetes-related difficulties, and the skills with children and their parents in testing the sugar level in blood and self-giving insulin injection. The problem-solving test was more difficult than to test children/parents' general information; in fact, mothers were more knowledgeable than fathers. Also, older children have more knowledge than young ones. The study showed that $80 \%$ of young children made mistakes in measuring their blood sugar levels and in self-giving insulin injections, while parents made $40 \%$ of the mistakes of the same skills.

In sum, there are some studies that focused on the awareness of students relating to diabetes and its causes, symptoms and treatments. However, this study tried to investigate the degree of knowledge of the students at TTU about diabetes. The researcher benefited from previous studies in developing this study instrument and comparing the results of this study with the other studies.

\section{Statement of the problem}

University graduates in general and those of educational majors in particular will be that pioneers of the educational process in the future. They are the ones almost in contact with our students; thus, the degree of their knowledge and awareness of diabetes should be confirmed. Statistics have approved that diabetes is one of the diseases that is clearly increasing, whilst the number of affected people is expected to increase in the future. This requires extensive awareness and knowledge for students about the symptoms, causes and treatments needed for it. This study came to identify the degree of knowledge of the students at the Faculty of Education at TTU of any medical information as to diabetes in terms of its causes, symptoms and treatment methods.

\section{Significance and Questions}

This study attempts to highlight an aspect of the topic dealing with, which is the degree the TTU students' knowledge of diabetes. The obvious lack of relevant studies and the need of the Arabic library for further studies create the importance of this study. In addition, this study contributes to providing stakeholders with appropriate decisions on necessary awareness rising about diabetes. In addition, it helps in developing new study plans for university students to increase their awareness about chronic diseases in general and diabetes in particular. The study limited to the undergraduate students enrolled at the Faculty of Educational science at TTU in the second semester of the academic year 2015/2016. The study attempted to answer the following four questions:

1. Are there statistical differences $(\alpha=0.05)$ in the degree of knowledge of the students at the Faculty of Education at TTU of diabetes due to first-degree relatives with diabetes?

2. Are there statistical differences $(\alpha=0.05)$ in the degree of knowledge of the students at the Faculty of Education at TTU of diabetes due to their gender?

3. Are there statistical differences $(\alpha=0.05)$ in the degree of knowledge of the students at the Faculty of Education at TTU of diabetes due to their major (Special Education and Classroom Teacher)? 


\section{Macrothink}

4. Are there statistical differences $(\alpha=0.05)$ in the degree of knowledge of the students at the Faculty of Education at TTU of diabetes due to their academic level (first, second, third, fourth)?

\section{Population and Sample}

The population of the study consisted of 491 students enrolled at the Faculty of Education at TTU in the second semester of 2016/2017. Table 1 illustrates the distribution of this population according to the variable of gender and major:

Table 1. Distribution of the population to gender and major

\begin{tabular}{lccccccccc}
\hline Major & \multicolumn{2}{c}{ First year } & \multicolumn{2}{c}{ Second year } & \multicolumn{2}{c}{ Third year } & \multicolumn{2}{c}{ Fourth year } & Total \\
& M & F & M & F & M & F & M & F & \\
Classroom teacher & 17 & 27 & 31 & 57 & 14 & 55 & 20 & 54 & 275 \\
Special education & 20 & 16 & 29 & 36 & 34 & 28 & 33 & 46 & 242 \\
Total & 37 & 43 & 60 & 93 & 48 & 93 & 53 & 100 & 517 \\
\hline
\end{tabular}

The sample of the study was selected by a random cluster method, regarding that each department was a unit of choice, taking into consideration the variables of gender and major. The sample was (171) male and female students, representing (.33) of the total population. Two questionnaires were designed, so as to get a final sample composed of (169) male and female students $(=32.6)$. Table 2 shows the distribution of the research sample of the study.

Table 2. Distribution of the research sample

\begin{tabular}{lccccccccc}
\hline \multirow{2}{*}{ Major } & \multicolumn{2}{c}{ First year } & \multicolumn{2}{c}{ Second year } & \multicolumn{2}{c}{ Third year } & Fourth year & Total \\
& M & F & M & F & M & F & M & F & \\
Classroom teacher & 7 & 17 & 10 & 14 & 7 & 18 & 4 & 12 & 89 \\
Special education & 16 & 11 & 6 & 10 & 9 & 9 & 9 & 10 & 80 \\
Total & 23 & 28 & 16 & 24 & 16 & 27 & 13 & 22 & 169 \\
\hline
\end{tabular}

Table (2) shows the number of the students in the Classroom Teacher Department as reaching 89 male and female students, while the number of the students in the Special Education Department was 80 students. The whole number of the sample was distributed as 51, 40, 43 and 35 for the first, second, third and fourth years respectively.

\section{Limitations of This Study}

The study limited to the undergraduate students enrolled at the Faculty of Education at TTU in the second semester of the academic year 2015/2016. 


\section{Method}

This section deals with the procedures of the study carried out by the researcher in attempting to answer the research questions above.

The instrument of the study was developed by referring to the relevant theoretical framework and such specialized diabetes centers as Diabetes and Hormone Centre of the Pacific and the National Centre for Diabetes, Endocrinology and Genetics (Jordan). The initial form of the questionnaire was offered to ten specialist referees to judge its validity for the purposes of this study. Also, the tool was applied to a pilot study of 20 male/female students in order to confirm its reliability.

After confirming the psychometric characteristics of the instrument, it was applied to the sample of the study consisting of 169 male/female students. The collected data was entered to computer software, and the research questions were accordingly answered. Eventually, in terms of statistical processing, the T-test was used to answer Questions nos. 1, 2 and 3 for independent samples, while the One-Way ANOVA test was used to answer Question no. 4.

\section{Instrument}

Having reviewed the literature related and such specialized diabetes centers as Diabetes and Hormone Center of the Pacific and the National Center for Diabetes, Endocrinology and Genetics (Jordan), a questionnaire was developed, it consists of 25 items, it divided into two groups: The items. 1-10 questions were given four-choice answers, and items number 11-25 were only true and false questions.

\section{Validity}

The questionnaire in its initial form was offered to ten specialized referees to express their views on how the items are valid and linguistically integral. Eighty (80\%) percent of them agreed to keep the instrument as is, while others requested deleting or replacing some of its paragraphs. Also, two items of the questionnaire were revised to keep the questionnaire with 25 items.

\section{Reliability}

The instrument was applied to a pilot sample consisted of 20 male/female students outside the research sample. The reliability of the instrument was calculated by using Cronbach's Alpha equation, representing $88 \%$, which was considerably a suitable value for the purposes of this study.

\section{Result}

The researcher entered the data into the computer software; the study reached the following results consequently according to its research questions.

First question: 'Are there any statistical differences $(\alpha=0.05)$ in the degree of knowledge of the students at the Faculty of Education at TTU of diabetes due to their first-degree relatives with diabetes?' To answer the first question, T-test was used for the independent samples. 
Table 3. T-test results for independent samples as to first-degree relatives

\begin{tabular}{lccccc}
\hline Relative & Mean & SD & T-value & $\begin{array}{c}\text { Degree of } \\
\text { freedom }\end{array}$ & $\begin{array}{c}\text { Level of } \\
\text { significance }\end{array}$ \\
& & & DF & Sig. \\
Diabetic relatives & 17.14 & 3.00 & 3.05 & 167 & .003 \\
Non-diabetic relatives & 15.82 & 2.59 & & & \\
\hline
\end{tabular}

The table above shows that there are statistically significant differences in the knowledge of the students about diabetes due to a first-degree relative with or without diabetes, and T-value was (3.05) and it has a statistical function at the significance level $(\alpha=0.05)$. These differences are in favor of the students with first-degree diabetic relatives, with a mean of 17.14 and a standard deviation of 3.00 .

Second question: 'Are there statistically significant differences $(\alpha=0.05)$ in the extent of knowledge of the students at the Faculty of Education at TTU of diabetes attributed to gender (male, female)?' In order to answer the second question, another T- Test was used for the independent samples, and the table below clarifies that.

Table 4. T-test results for the independent sample related to gender

\begin{tabular}{lccccc}
\hline Gender & Mean & SD & T-value & $\begin{array}{c}\text { Degree of } \\
\text { freedom }\end{array}$ & $\begin{array}{c}\text { Level of } \\
\text { significance }\end{array}$ \\
& & & DF & Sig. \\
Males & 16.46 & 2.88 & .846 & 167 & .39 \\
Females & 16.26 & 2.84 & & & \\
\hline
\end{tabular}

Table 4 shows that there were no statistically significant differences in the extent of knowledge of the students at the Faculty of Education at TTU of diabetes attributed to the student's gender (male or female). T-value was (.846) and it is not statistically significant at the level of significance $(\alpha=0.05)$.

Third question: Are there statistical differences $(\alpha=0.05)$ in the degree of knowledge of the students at the Faculty of Education at TTU of diabetes due to thier major (Special Education and Classroom Teacher)?

To answer the third question, $\mathrm{T}$ - test was used for the independent samples, and the table below clarifies that. 
Table 5. T-test results for the independent samples related to major

\begin{tabular}{lccccc}
\hline Major & Mean & SD & T-value & Degree of & Level of \\
& & & freedom & significance \\
& & & DF & Sig. \\
Special education & 16.32 & 2.89 & .786 & 167 & .433 \\
Classroom teacher & 16.58 & 2.83 & & & \\
\hline
\end{tabular}

Table 5 shows that there were no statistically significant differences in the extent of knowledge of the students at the Faculty of Education at TTU of diabetes attributed to major (Special Education or Classroom Teacher), (T) value (.786) is not statistically significant at the level of significance $(\alpha=0.05)$ as well.

Fourth question: Are there statistical differences $(\alpha=0.05)$ in the degree of knowledge of the students at the Faculty of Education at TTU of diabetes due to their academic level (first, second, third, fourth)? To answer the fourth question, the One-Way analysis of variance (One-Way ANOVA) is used, and the table below clarifies the mean values.

Table 6. Means and SDs due to academic year

\begin{tabular}{lcc}
\hline Academic year & Mean & SD \\
$1^{\text {st }}$ year & 15.58 & 3.14 \\
$2^{\text {nd }}$ year & 16.80 & 2.98 \\
$3^{\text {rd }}$ year & 16.81 & 2.33 \\
$4^{\text {th }}$ year & 16.71 & 2.72 \\
\hline
\end{tabular}

The table 6 shows that the third-year students of the Faculty of Education at TTU had more information about diabetes more than the first, second or fourth-year ones. The mean reached 16.81 and the SL was 2.33. Also, the first-year students had the least mean of 15.58 and SD of 3.14. In order to identify the difference of significance of the mean, the researcher used the One-Way ANOVA test as shown in Table 7: 
Table 7. Results of the one-way ANOVA test

\begin{tabular}{lccccc}
\hline Sources & Sum of squares & $\begin{array}{c}\text { Degree of } \\
\text { freedom }\end{array}$ & Mean square & T-value & $\begin{array}{c}\text { Level of } \\
\text { significance }\end{array}$ \\
& & DF & & Sig. \\
Level of education & 50.764 & 3 & 16.921 & 2.111 & .101 \\
Error & 1322.407 & 165 & 8.015 & \\
Total & 46939.00 & 169 & & \\
Corrected total & 1373.172 & 168 & & \\
\hline
\end{tabular}

The table (7) shows that there were no statistically significant differences in the extent of knowledge of the students at the Faculty of Education at TTU due to the academic year. However, the test value $(\mathrm{t})$ is (2.11), which is not statistically significant at the level of significance $(a=0.05)$.

\section{Discussion}

The results of the study were discussed in light of its general aims and research questions as follows:

The results of the first question showed that there were statistically significant differences in the degree of knowledge of the students at the Faculty of Education at TTU in diabetes due to diabetic relatives. However, these differences were attributed to the behalf of students with first-degree relatives with diabetes. This result is due to the fact that students' knowledge of diabetes through the environment of a family which has a member with diabetes, the reason that gave them the knowledge and experience about this disease. In fact, the students who did not have any family member with diabetes showed less knowledge about the disease. The result is attributed to the absence of health and education awareness about diabetes and the absence of curriculum awareness about the disease.

For the second question, the results showed that there were no statistically significant differences in the degree of knowledge of the students at the Faculty of Education at TTU in diabetes due to gender. The result is attributed to the fact that university and school curriculums are unified to both genders. The diagnoses of diabetes came from the history of a family that has a diabetic member. The results of the third question showed that there were no statistically significant differences in the degree of knowledge of the students at the Faculty of Education at TTU in diabetes due to major (Special Education or Classroom Teacher). The result is attributed to the lack of sufficient information in curriculum about diabetes.

Lastly, no statistically significant differences were found according to the results of the fourth question in the degree of knowledge of the students at the Faculty of Education at TTU in diabetes due to academic year. This result could be attributed to the fact that the study plan including either specialized subjects or general requirements that university students receive 
lacks any in-depth information related to diabetes, except for some surface information that is negligible in the curricula of the Faculty of Education.

\section{Conclusion}

This study aimed at investigating the degree of knowledge of the students at Tafila Technical University (TTU) about diabetes in terms of its causes, symptoms and treatments. The results of the study showed that there were statistically significant differences in the degree of knowledge of the students about diabetes, attributed to first-degree relatives with diabetes or not. In addition, the results also showed that there were no statistically significant differences in the degree of knowledge about diabetes attributed to gender, major and academic year

\section{Recommendations}

In conclusion, the present study provides the following set of recommendations: 1) adding study materials related to the public health culture, 2) holding awareness-raising and educational sessions at college and university levels in relation to infectious and non-infectious diseases, and 3) establishing a comprehensive national program to identify diabetes in terms of causes, symptoms and methods of treatment.

\section{References}

Ajlouni, K., Khader, Y., Batieha, A., Ajlouni, H., \& El-khateeb, M. (2007). The increase in the incidence of diabetes in Jordan during 10 years. Journal of Diabetes and its Complication, 22, 110 .

Alhameed, M. (2008). Diabetes, its causes, complications and treatment. King Fahad National Library, Riyadh.

Alhayari, A. (2002). The extent affect on children with diabetes and their families, and the role of social work in enabling them to deal with the disease: A study on a sample of resident children with diabetes and reviewers of University Hospital of Jordan from the age of (6-12) years. Unpublished Master Thesis, University of Jordan, Amman.

Almishal, A. (2010). Diabetes in the Arab Region. Health and Diabetes Journal, $2^{\text {nd }}$ issue, National Centre for Diabetes, Endocrinology and Genetics, Amman, Jordan.

Arshidat, G. (2007). Effect of Exercise and Diet on Type 2 Diabetes. Unpublished Master Thesis, University of Jordan, Amman.

Bennett, S., Polak, T., \& Arland, L. (1982). Cognitive and Behavioral Knowledge about Insulin- Dependent Diabetes among Children and Parents. Department of Psychiatry, University of Florida Health Center, Gaivesville.

Brown, D., Mokdad, A., Walke, H., As'ad, M., Al-Nsour, M., Zindah, \& M.,Belbeisi, A. (2009). Projected Burden of Chronic, Noncommunicable Diseases in Jordan. Preventing Chronic Disease, 6(2), A78. 
Centres for Disease Control and Prevention, National Center for Chronic Disease Prevention and Health Promotion Division of Diabetes Translation (2007). Take Charge of Your Diabetes. Atlanta, U.S Department of Health and Human Services.

Gunay., T., Ulusel., B., Velipasaoglu., S., Unal., B., \& Ucku., R. (2006) Factors affecting adult knowledge of diabetes in Narlidere Health District, Turkey. Acta Diabetologica, 43, 142-147. https://doi.org/10.1007/s00592-006-0230-6

Information Association (2010). What is diabetes? Translated by the Association of the health literacy with diabetes. Australia. Retrieved from: http://multiculturalportal.ndss.com.au/globalassets/ndss/ndss-what-is diabetes-arabic.pdf.

Lancet, (1998). Effect of intensive blood-glucose control with metformin on complications in overweight patients with type 2 diabetes (UKPDS 34). UK Prospective Diabetes Study (UKPDS) Group, 7, 854-865

The National Center for Diabetes, Endocrinology and Genetics (2016). Diabetes, Amman, Jordan.

The National Center for Diabetes, Endocrinology and Genetics (A) (2011). Diabetes Types and Treatment. Amman, Jordan.

The National Center for Diabetes, Endocrinology and Genetics (B). (2011). Diabetes and its symptoms. Amman, Jordan.

World Health Organization (2016). Diabetes. Retrieved from: http://www.who.int/mediacentre/factsheets/fs312/ar. 